\section{Commentary: Experience and expertise prevail when guidelines fail}

\author{
Eric J. Charles, MD, PhD, and James J. Gangemi, MD
}

In this issue of the Journal, Lee and colleagues ${ }^{1}$ describe the management of a 15-year-old patient with infective endocarditis of the left ventricular outflow tract (LVOT) in the setting of hypertrophic cardiomyopathy (HCM). The reported operative procedure is straightforward; however, the clinical scenario is rather unique. As such, the authors are to be commended for their astute clinical judgment and decision to intervene, resulting in a favorable outcome. However, we believe there were opportunities to intervene earlier and thus present 2 alternative treatment strategies below based on our institution's approach to patients with $\mathrm{HCM}$ and those at risk for endocarditis.

The annual incidence of pediatric HCM is estimated at 4.7 cases per 1 million children. ${ }^{2}$ Pharmacologic and invasive management strategies are used depending on the presence of obstructive physiology and symptoms. ${ }^{3}$ The patient described in this case report was treated with beta blockade and an implantable defibrillator, which is indicated in appropriate patients to mitigate the $9.1 \% 5$-year risk of sudden cardiac death. ${ }^{4}$

The surgical management was successful, but given the history of progressive LOVT obstruction with aortic and mitral valve distortion in the preceding 4 years, should the patient have been operated on before developing endocarditis? The authors report LVOT peak gradients of 96 to $121 \mathrm{~mm} \mathrm{Hg}$, aortic insufficiency, and mitral regurgitation. Lacking is a description of the patient's symptoms, which can only be inferred based on the use of beta blockade, a Class IIb recommendation for pediatric patients with angina

\footnotetext{
From the Division of Cardiac Surgery, Department of Surgery, University of Virginia, Charlottesville, Va.

Disclosures: The authors reported no conflicts of interest.

The Journal policy requires editors and reviewers to disclose conflicts of interest and to decline handling or reviewing manuscripts for which they may have a conflict of interest. The editors and reviewers of this article have no conflicts of interest.

Received for publication Oct 7, 2020; revisions received Oct 7, 2020; accepted for publication Oct 20, 2020; available ahead of print Oct 22, 2020.

Address for reprints: James J. Gangemi, MD, Department of Surgery, University of Virginia, PO Box 800679, Charlottesville, VA 22908 (E-mail: jgangemi@ virginia.edu).

JTCVS Techniques 2020;4:283-4

2666-2507

Copyright (C) 2020 The Authors. Published by Elsevier Inc. on behalf of The American Association for Thoracic Surgery. This is an open access article under the CC BY-NCND license (http://creativecommons.org/licenses/by-nc-nd/4.0/).

https://doi.org/10.1016/j.xjtc.2020.10.031
}

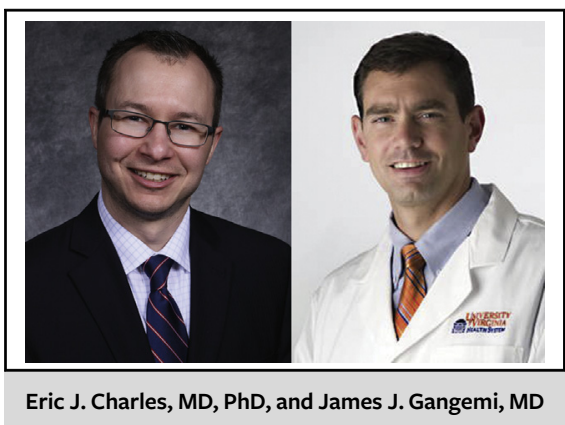

CENTRAL MESSAGE

Experience and expertise must drive management strategy when guidelines are nonexistent, as in this case of a pediatric patient with hypertrophic cardiomyopathy and endocarditis.

or dyspnea. ${ }^{3}$ Based on the history and hemodynamics provided, performing septal myectomy earlier during this patient's clinical course would have been reasonable and may have prevented the development of endocarditis. At our institution, a pediatric patient with a persistent gradient over 90 to $100 \mathrm{~mm} \mathrm{Hg}$ or symptoms despite maximum pharmacologic therapy would be discussed at multidisciplinary conference and likely treated with surgical intervention.

In addition, a discussion is warranted regarding the use of prophylactic antibiotics in patients with HCM. The authors report that the patient underwent "extensive dental work" but did not receive prophylactic antibiotics. According to the 2016 American Association for Thoracic Surgery guidelines, antibiotics are recommended for patients with congenital heart disease only if they have cyanotic disease or have undergone repair with prosthetic material. ${ }^{5}$ Likewise, although the National Institute for Health and Care Excellence guidelines acknowledge that patients with $\mathrm{HCM}$ are at increased risk of endocarditis, prophylaxis is not routinely recommended. ${ }^{6}$ Nonetheless, at our institution, patients with HCM and evidence of LVOT obstruction would receive prophylactic antibiotics, as we believe the benefits outweigh the risks for this patient population.

Guidelines specific for pediatric patients with HCM and those with congenital heart disease undergoing dental procedures are not as robust as we would like, making it a necessity to thoroughly weigh the risks and benefits of various treatment options. This case report highlights that necessity. Although the treatment strategy and timing of intervention 
can be debated, we commend the authors on their successful management of this unique clinical scenario.

\section{References}

1. Lee ME, Kemna M, Schultz AH, McMullan DM. A rare pediatric case of left ventricular outflow tract infective endocarditis in hypertrophic cardiomyopathy. J Thorac Cardiovasc Surg Tech. 2020;4:281-2.

2. Colan SD, Lipshultz SE, Lowe AM, Sleeper LA, Messere J, Cox GF, et al. Epidemiology and cause-specific outcome of hypertrophic cardiomyopathy in children: findings from the pediatric cardiomyopathy registry. Circulation. 2007;115:773-81.

3. Gersh BJ, Maron BJ, Bonow RO, Dearani JA, Fifer MA, Link MS, et al. 2011 ACCF/AHA guideline for the diagnosis and treatment of hypertrophic cardiomyopathy: a report of the American College of Cardiology Foundation/American
Heart Association task force on practice guidelines. J Am Coll Cardiol. 2011; 58:e212-60.

4. Miron A, Lafreniere-Roula M, Fan CS, Armstrong KR, Dragulescu A, Papaz T, et al. A validated model for sudden cardiac death risk predication in pediatric hypertrophic cardiomyopathy. Circulation. 2020;142:217-29.

5. Petterson GB, Coselli JS, Hussain ST, Griffin B, Blackstone EH, Gordon SM, et al. 2016 the American Association for Thoracic Surgery (AATS) consensus guidelines: surgical treatment of infective endocarditis: executive summary. $J$ Thorac Cardiovasc Surg. 2017;153:1241-58.e29.

6. National Institute for Health and Care Excellence. Prophylaxis against infective endocarditis: antimicrobial prophylaxis against infective endocarditis in adults and children undergoing interventional procedures (CG64). National Institute for Health and Care Excellence; 2008. Available at: http://www.nice.org.uk/ guidance/CG64. Accessed October 5, 2020. 